This is an author produced version of a paper published in Patient Education and Counseling. This paper has been peer-reviewed but does not include the final publisher proof-corrections or journal pagination.

Citation for the published paper:

Bengtsson, Mariette and Ulander, Kerstin and Börgdal, Elisabet Bergh and

Christensson, Ann-Christine and Ohlsson, Bodil

"A course of instruction for women with irritable bowel syndrome."

Patient Educ Couns. 2005 Aug 9; [Epub ahead of print]

http://dx.doi.org/10.1016/j.pec.2005.06.015

Access to the published version may require journal subscription.

Published with permission from: Elsevier 


\title{
A COURSE OF INSTRUCTION FOR WOMEN WITH IRRITABLE BOWEL SYNDROME
}

\author{
Mariette Bengtsson $^{1,2}$, Kerstin Ulander ${ }^{2}$, Elisabet Bergh Börgdal ${ }^{1}$, Ann-Christine \\ Christensson $^{3}$, and Bodil Ohlsson ${ }^{1}$ \\ ${ }^{1}$ Department of Clinical Sciences, Malmö, Lund University, Sweden \\ ${ }^{2}$ Department of Health Sciences, Faculty of Medicine, Lund University, Sweden \\ ${ }^{3}$ Department of Surgery, Malmö, Lund University, Sweden
}

Correspondence to:

Mariette Bengtsson, University Hospital Ing 35, S-205 02 Malmö, Sweden

Phone +46 40333683 Fax +46 40337300

mariette.bengtsson@skane.se 


\section{A COURSE OF INSTRUCTION FOR WOMEN WITH IRRITABLE BOWEL SYNDROME}

\section{Abstract}

Objective. The aim of this study was to determine the effects a course of instruction about Irritable Bowel Syndrome (IBS) might have on symptoms, psychological wellbeing, and medical care requirements in these patients. Methods. Twenty-nine women with IBS participated in a programme of instruction on medical care, physical activity, stress-management, diet and health-insurance. The women completed the Gastrointestinal Symptom Rating Scale and the Psychological General Well-Being Index and provided information about their requirements of medical care before and after the course. Results. Twenty-three of the women included, completed the questionnaires at 12 months after the course. When comparing these values to those at baseline, there were improvements in abdominal pain $(p<0.037)$ and vitality $(p<0.045)$ as well as a reduction in the number of visits to physicians $(p<0.037)$ and dieticians $(p<0.042)$. Conclusion. Information related to the disease, might help women with IBS to perceive less pain and more vitality and thereby experience a higher quality of life. Practice Implications. A course of instruction for patients with IBS may be of benefit for the patients, and could be a part of a multicomponent approach in the treatment of this patient group.

Keywords: Course of Instruction, Irritable Bowel Syndrome, Pain, Vitality, Quality of Life 


\section{Introduction}

Irritable Bowel Syndrome (IBS) is a global, functional disorder with symptoms attributable to the mid or lower gastrointestinal tract. It is characterized by abdominal pain, bloating and disturbed defecation [1], and the symptoms vary in intensity over time [2]. A patient's physical, mental and social health is affected by the disorder [36] and it is well known that there is an interaction between IBS and psychiatric disorders [7-10]. The diagnosis IBS can not be confirmed until other diseases have been excluded [11], and there are various theories relating to the cause of IBS but none stands out as the most plausible. Today there is no cure, and the treatment of symptoms is not sufficiently effective, but patients may have some benefit from several types of drugs [12]. The disorder costs the community vast sums of money in terms of repeated visits to physicians and other health care professionals, investigations and medication, and also due to loss of productivity since persons who suffer from IBS are often absent from work due to their symptoms [5, 13-15].

Patients with IBS have to cope not only with their symptoms but also with the often relatively unsympathetic attitude of family and friends [16]. Women with IBS have reported that they have been offended and felt misunderstood because doctors and nurses have not taken their problems seriously [16-18]. Patients with IBS are not always familiar with the diagnosis and with all that it implies and want more information and instruction about the disorder $[16,19]$.

Instruction of patients has become an important part of health promotions worldwide, and this instruction is often focused on patients with specific, global conditions [20-22]. However, the effects of the instruction on the patients' health has been poorly evaluated. In the USA courses of instruction for patients with IBS have been given. In a single group lesson, patients were taught about health-promoting 
modifications of their lifestyle, stress management, exercise and diet, as well as pharmacological treatments in connection with IBS. The patients participating improved in some of their health-promoting behaviour and their symptoms improved six months after completing the course $[23,24]$. No articles on the long-term outcome of information to patients or self-study groups have to our knowledge been published.

The aim of this study was to determine the effects of systematic information over time on the long-term outcome on symptoms, psychological well-being, health care requirements, medication, and sick-leave from work or school in Swedish women with IBS.

\section{Methods}

\subsection{Patients and baseline assessments}

A search for participants, who had been diagnosed as having IBS, was made among all patients who had visited the Department of Medicine at Malmö University Hospital between 1 January 1998 and 31 August 2002. All identified patients had been referred to the hospital from primary care centres or general practitioners. The diagnosis was verified by the patients' medical records. Patients who also had other severe chronic diseases such as liver or kidney diseases, chronic pulmonary or heart diseases, serious mental diseases or seizure disorders, were excluded. Only few men with IBS were identified, and since there are differences related to IBS between women and men [25-27] only women were selected for this study. Further, we thought it would be easier for the women to discuss their problems in the group if only women were included. By a review of the register of diagnoses, 57 women 
between 18 and 65 years of age were found who had been diagnosed as having IBS. These were invited to take part in a course of instruction called The IBS School.

\subsection{Study design}

The study protocol was approved by the local Ethics Committee of the Lund University, and all participants gave written, informed consent before taking part in this study. Data were collected between November 2002 and May 2004. Before starting the course of instruction, questionnaires were sent by mail to all the participants. The women completed two self-administered questionnaires; the Gastrointestinal Symptom Rating Scale (GSRS) and the Psychological General WellBeing Index (PGWB). They also provided information about their health care consumption, medications, and sick-leave from work or school during the previous year in a third questionnaire. Directly after the women had finished the programme, they completed a questionnaire on the content of the instruction programme. This questionnaire was completed at the hospital. To follow up the women's symptoms and psychological well-being, they completed the questionnaires GSRS and PGWB at 1,6 and 12 months after finishing the programme. After 12 months the women again provided information about their health care consumption, medications, and sick-leave. All follow-up questionnaires were sent to the participants by mail together with written information. If a response was not received within four weeks, a reminder and a new packet of questionnaires were sent out.

The primary endpoint was to investigate whether women with IBS find their symptoms and psychological well-being improved after taking part in a course of instruction. The secondary endpoints were to find whether there were any changes in the women's requirements of health care and medications and in the frequency of sick-leave. 


\subsection{Questionnaires}

The GSRS is a Swedish disease-specific questionnaire designed to evaluate gastrointestinal symptoms. It was originally constructed as an interview-based rating scale [28], and was later modified to become a self-administered questionnaire [29, 30]. The questionnaire includes 15 items scored on a 7-grade Likert scale, giving a total range-value of between 15 and 105, and the higher the score, the more pronounced are the symptoms. The items are divided into five dimensions; Abdominal Pain Syndrome (3 items), Reflux Syndrome (2 items), Indigestion Syndrome (4 items), Diarrhoea Syndrome (3 items), and Constipation Syndrome (3 items).

The PGWB Index is a generic instrument developed to provide a questionnaire to be used to measure positive and negative aspects of subjective well-being and distress [31]. The questionnaire includes 22 items scored on a 6-grade Likert scale, which gives a total range-value of between 22 and 132, and the higher the value, the better is the patient's psychological well-being. The items are divided into six dimensions: Anxiety (5 items), Depressed Mood (3 items), Positive Well-being (4 items), Self-Control (3 items), General Health (3 items) and Vitality (4 items). The PGWB Index as well as the GSRS have been tested on a Swedish population and norm values have been described by Dimenäs et al. [32].

For an objective evaluation of the participants' health care requirements related to IBS, a questionnaire, designed as a case report form, was developed for this study. The questionnaire has been judged by experts in the field and evaluated for face validity. The questionnaire was divided in three parts; health care consumption, pharmacological treatment, and sick-leave from work or school. The participants left 
information about visits to health care professionals or other persons related to their treatment of IBS and number of visits, doses and name of pharmacological and naturopathic treatment as well as number of days of treatment in hospitals and number of days of sick-leave.

The questionnaire on the content of the course of instruction includes in total 21 items divided in two parts. In part one (total 15 items), are there three items about each issue in the programme; one item graded on a four graded Likert scale and two open items. In part two, there are six open items in which the respondents could write their own comments of their perception of the programme; positive and negative aspects of the course, suggestions for improvements, recommendations to other, fulfilled expectations and pleasure of the information. This questionnaire has been judged by experts in the field, evaluated for face validity and has been used for several years for the same purpose for patients with Inflammatory Bowel Diseases [33].

\subsection{The Programme of Instruction}

The course of instruction was developed and given by a group of professional clinicians employed at the Department of Medicine, Division of Medical Gastroenterology at Malmö University Hospital, specialized in IBS, and with a specific interest in instruction for patients with this disorder. This group of lecturers (all women) included one physician, two registered nurses, one dietician, and one medical social worker. One of the nurses, apart from lecturing, coordinated all practical matters and was present throughout the course to assist the participants. The programme consisted of lectures on various subjects, including medical care, physical activity, stress management, diet and health insurance. Previous studies have shown that patients with IBS may benefit from more information on these 
subjects, for instance, the fact that regular physical activity can reduce pain [23] as well as fatigue [34] and that stress-management can reduce the severity and the frequency of the attacks [35]. The four lectures, each of two hours' duration, included a short break during which the participants could have informal discussions, were held in a lecture room at the hospital. Lecturing with an interactive approach, group exercises and written material were used. Self-help brochures and summaries of each lecture were provided.

After a short introduction to the programme, led by the coordinating nurse, the physician gave the first lecture, explaining that IBS symptoms constitute a recognised disorder, and discussed anatomy and physiology, the patho-physiology of functional bowel disorders such as visceral hypersensitivity and dysmotility [36-38], and the investigational procedure and treatment of this entity. The second lecture was conducted by the two registered nurses with specialized knowledge and long experience of physical activity and stress-management. They focused on how to initiate physical activities and gave an overview of stress and stress-management. During this lesion there was also time for the participants to practice diaphragmal breathing and muscle relaxation. The dietician took the third lesson and focused on nutritional requirements, healthy eating habits, regular meals as well as diets suitable for patients with IBS. The first part of the final lecture was held by the medical social worker. She focused on the Swedish health care insurance system and the patient's rights as well as private insurances. The participants were informed about The Swedish Association of People with Stomach and Bowel Diseases and the ways in which the association can be of help to patients with IBS and their relatives. The second part of the last session consisted of a group discussion between the participants and all the lecturers. 


\subsection{Statistical analyses}

Statistical analyses were carried out using SPSS 11.0 for Windows ${ }^{\circledR}$. Friedman’s test was used to examine whether there were any differences over the time in the patients' symptoms and well-being evaluated by the GSRS and PGWB Index. The Wilcoxon Signed Rank test was used to assess the changes in the long-term outcome of symptoms and well-being at 12 months after finishing the instruction course compared to baseline, as well as to assess changes in care consumption, medications, and sick-leave during the year before and after the course. Spearman's test was used as a correlation test. A $p$ value of $<0.05$ was considered statistically significant. The women's perception of the content of the programme was presented descriptively.

\section{Results}

\subsection{Patients' characteristics}

Of the 57 women with IBS identified, 34 accepted participation in our programme, but four of them did not come to the initial meeting and one woman did not complete the programme. Thus, 29 women were included in this study. Of the other 23 women, eight did not accept the invitation, the reasons given were lack of time, being not interested $(n=7)$, not having symptoms at the time $(n=6)$ or that they already had adequate knowledge about the syndrome $(n=2)$.

Of the 29 women included (median age 40, range 20-65 years) nearly half of them ( $n=13)$ were in the age group of 34-47 years, and of the remaining 16 women 8 were younger and 8 were older than this group. They had suffered from IBS between 4-50 years, mean 12 years. The women participating were consecutively divided into three groups with 8 to 11 participants in each group. According to the women's 
medical records, the main problem stated concerning why they consulted a medical patrician at baseline was alternating constipation and diarrhoea $(n=13)$, diarrhoea $(n=7)$, constipation $(n=5)$ or pain $(n=4)$.

\subsection{Symptoms and psychological well-being}

The response rates for the questionnaires GSRS and PGWB are presented in Figure 1. and the results in Table 1 . Of the 29 women participating, 18 completed all the GSRS and the PGWB follow-up questionnaires. There were no significant changes in the women's symptoms and psychological well-being over time in any of the domains in either the GSRS or the PGWB Index according to Friedman's test (data not shown). However, when the values at 12 months were compared (Wilcoxon Signed Rank test) with those at baseline $(n=23)$, there were statistically significant improvements observed in their statements on abdominal pain $(p<0.037)$ and on vitality ( $p<0.045$ ) (Table 1$)$. There was a correlation according to Spearman's correlation test between these domains, at baseline $(p<0.032)$ as well as at 12 months $(p<0.049)$, with less pain and greater vitality.

\subsection{Care requirements, medication and sick-leave from work or school}

The health care consumption questionnaire had a lower response rate $(n=20)$ than the questionnaires GSRS and PGWB (n=23) (Figure 1) at 12 months, even though all three questionnaires were supposed to be completed at the same time.

There were statistically significant differences between the women's care consumption during the 12 months before the programme compared to the 12 months afterwards (Wilcoxon Signed Rank test) with reduces in the total numbers of visits to physicians $(p<0.037)$ and to dieticians $(p<0.042)$ (Table 2$)$. 
The women in the present study used five groups of pharmaceutical drugs before as well as after the programme, although some non-significant changes had been made (Table 3). One woman had stopped using an antidepressant drug, and two women had started to use stimulant laxatives after having been given information on how these drugs are to be used. Only six of the 29 women used naturopathic preparations either before or after the programme (Table 3).

There were no statistically significant changes between the women's reported hospitalisation during the year before (mean at baseline $<0.25$ days/year) compared to the year after the course, or absence from work/school (mean at baseline $<3.5$ days/year) according to Wilcoxon Signed Rank test (Table 4).

\subsection{The participants' perception of the Course of Instruction}

After the course, 24 of the women answered the questionnaire on the content of the programme (Figure 1). They stated that the entire information, including the written material, gave them a good understanding of their health problems. It was also a step ahead for them to change their lifestyle, but they did not mention in what way. Four women commented that they would have liked to have been given this information at the time they were diagnosed. Fifteen women mentioned that they enjoyed meeting others with the same disorder, and to share experiences with them. Seven women wrote that they felt it was positive that the health professionals showed interest in them and tried to do something to help them live with their bowel problems. Furthermore, nine women mentioned that they considered the programme to be too short. They had wanted more time to practice stress-management exercises, and more instruction on coping strategies. Three of the women stated that they would 
have preferred the groups to be smaller, as they experienced difficulty in speaking about their problems with so many unfamiliar persons.

\section{Discussion and Conclusion}

\subsection{Discussion}

The women in the present study were informed about medical care, physical activity, stress management, and diet as well as about health insurance, and how these subjects affect and interact with health. One year after the women had completed the course, there was a trend towards less abdominal pain and experiences of more vitality according to the GSRS and the PGWB than before they started the programme. The symptoms in patients with IBS normally vary in intensity over time [2]. However, only a few percent is healed every year within the first five years, those with longer duration have a very stable disease [39]. Since the women in the present study had had their symptoms for several years, mean 12 years, it is not plausible that the observed improvement is a spontaneous recovery.

This course was developed as a rather simplex concept that can be hold at every primary care centre or hospital after education of the health professionals. It consisted of several factors; the patients got information about their disease and about how to manage and handle the symptoms on their own, they got attention from healt care providers and opportunity to meet others with the same trouble. It is difficult to say what the most important of the instructions was, maybe it was the composition of diverse aspects that was important. In their own description the women mentioned that they had appreciated all the different components given concerning their bowel problems. Patients with IBS need to get their aggravated symptoms confirmed and to be aware that their condition is a genuine but harmless 
disorder [19]. From experience we know that persons with IBS sometimes associate their bowel symptoms with serious diseases, for example cancer, and this causes unnecessary anxiety. Many patients with IBS assert that various foods, especially those rich in carbohydrates and fat, aggravate their symptoms [40]. It is difficult to give general dietary advice to persons with IBS, since the research within this field is rudimentary. However, the patients were interested in how they could change their diet in hop to feel better. According to other studies [23, 24] health-promoting behaviour in women with IBS can be improved by education. Of the women who took part in the Course of Instruction, 16 have been followed up at the hospital. Out of these, 14 have told us that they could handle better with their bowel problems after taken part in the course. Further, some have made some life-tyle changes with increased physical activity, stressmangement and changed food habits. Instruction in groups may be appropriate for some patients with IBS, and may be preferable to individual education. Furthermore, a group instruction is more cost-effective than individual consultations.

During the programme, the participants had the opportunity to meet diverse categories of health professionals, with the consequence that fewer consultations for advice were sought after the completion of the programme. Similar results have been presented in other studies [41] who reported that well informed patients were associated with fewer follow-up visits. Apart from increased knowledge, the characteristics of the symptoms as well as their duration may also influence the patients' need of consultations [2, 26].

The participants had made some small changes after the lecture on pharmacological treatment. Two women were no longer afraid to use stimulant laxatives after the information that these drugs probably do not harm the bowels [42]. 
Three of the six women who had used antacidas and ulcer healing drugs had stopped using them after the programme since they were informed about that these drugs are of no benefit compared to placebo in functional diseases [43].

The total number of reported days of sick-leave from work or school due to bowel symptoms had not changed, in spite of the fact that the women had been given further information on their situation concerning health insurances. This might be due to that the women reported an initial low average rate absences, $<3.5$ days/year, which could be compared to 4.4 days/year for women without IBS [44].

The women who were included were identified from a register of diagnoses at a university hospital. However, patients with IBS are often given their diagnosis at a primary care centre and only a minority of them is referred to the hospital for a second opinion. In general, hospital outpatients have more severe symptoms and less psychological well-being than patients being treated at a primary care centre [26, 45]. It is possible that the outcome of this study would have been different if patients from primary care centres had been included. Our next study will therefore include patients at primary care centres, who might gain greater benefit from the information than hospital outpatients. The participants also suggested that this programme should be given to all patients directly after they have been informed of their diagnosis. Nearly half of the women identified, who were offered participation in the programme, did not accept this offer. Whether or not the women who participated were generally more interested in further information and willing to make life-style changes is unknown.

The present study has limitations. This study was a non-randomized, longitudinal study, without control group. It is difficult to provide appropiate and credible control groups for alternative therapies. Instead, many studies prefer a 
longer follow-up to compensate for the absence of control group [23, 24, 46]. The placebo effect in IBS is high [47] and might be a risk also in this study. In a previous study [48] the participants perceived a better health when they were included in a clinical drug trial, already during the screening, before the introduction of the drug. If a control group had been used, waiting for instruction in 12 months, there had still been a risk of confounding placebo effect as the patients had been given some attention during these months. This attention was one of the components in the course.

\subsection{Conclusion}

Evaluation of this course of instruction showed that information led to a trend for women with IBS to perceive less pain and more vitality, and thereby experience a higher quality of life. Since the sample was small, further studies have to be performed.

\subsection{Practice Implications}

Patient education is becoming more and more common [49]. If this type of course of instruction is of benefit for patients with IBS when further evaluated, these courses should be established as part of the ordinary treatment. A multicomponent approach including a course of instruction could then be held at primary care centres as well as at hospitals by educated health professionals.

\section{Acknowledgment}

We wish to thank Professor Stefan Lindgren for his support and his approval to let us conduct the Course of Instruction. 


\section{References}

[1] Thompson WG, Longstreth GF, Drossman DA, Heaton KW, Irvine EJ, MullerLissner SA. Functional bowel disorders and functional abdominal pain. Gut 1999;45:1143-7.

[2] Mearin F, Baró E, Roset M, Badia X, Zárate N, Perez I. Clinical patterns over time in irritable bowel syndrome: symptom instability and severity variability. Am J Gastroenterol 2004;99:113-21.

[3] Whitehead WE, Burnett CK, Cook EW, Taub E. Impact of irritable bowel syndrome on quality of life. Dig Dis Sci 1996;4:2248-53.

[4] Hahn BA, Yan S, Strassels S. Impact of irritable bowel syndrome on quality of life and resource use in the United States and United Kingdom. Digestion 1999;60:77-81.

[5] Creed F, Ratcliffe J, Fernandez L, Tomenson B, Palmer S, Rigby C, Cuthrie E, Read N, Thompson D. Health-related quality of life and health care cost in severe refractory irritable bowel syndrome. Ann Intern Med 2001;134:860-8.

[6] Coffin B, Dapoigny M, Cloarec D, Comet D, Dyard F. Relationship between severity of symptoms and quality of life in 858 patients with irritable bowel syndrome. Gastroenterol Clin Biol 2004;28:11-5.

[7] Lydiard RB. Anxiety and the irritable bowel syndrome: psychiatric, medical, or both? J Clin Psychiatry 1997;58:51-8.

[8] Jarrett M, Heitkemper M, Cain KC, Tuftin M, Walker EA, Bond EF, Levy RL. The relationship between psychological distress and gastrointestinal symptoms in women with irritable bowel syndrome. Nurs Res 1998;47:154-61. 
[9] Locke GR 3rd, Weaver AL, Melton LJ 3rd, Talley NJ. Psychosocial factors are linked to functional gastrointestinal disorders: a population based nested case-control study. Am J Gastroenterol 2004;99:350-7.

[10] Folks DG. The interface of psychiatry and irritable bowel syndrome. Curr Psychiatry Rep 2004;6:210-5.

[11] Talley NJ, Spiller R. Irritable bowel syndrome: a little understood organic bowel disease? Lancet 2002;360:555-64.

[12] Talley NJ. Evaluation of drug treatment in irritable bowel syndrome. Br J Clin Pharmacol 2003;56:362-9.

[13] Drossman DA, Li Z, Andruzzi E, Temple RD, Talley NJ, Thompson G, Whitehead WE, Janssens J, Funch-Jensen P, Corazziari E, Richter JE, Koch GG. U.S householder survey of functional gastrointestinal disorders: prevalence, sociodemography and health impact. Dig Dis Sci 1993;38:1569-80.

[14] Talley NJ, Gabriel SE, Harmsen WS, Zinsmeister AR, Evans RW. Medical costs in community subjects with irritable bowel syndrome. Gastroenterology 1995;109:1736-41.

[15] Zacker C, Chawala AJ, Wang S, Albers LA. Absenteeism among employees with irritable bowel syndrome. Manag Care Interface 2004;17:28-32.

[16] Dancey CP, Backhouse S. Towards a better understanding of patients with irritable bowel syndrome. J Adv Nurs 1993;18:1443-50.

[17] Meadows LM, Lackner S, Belic M. Irritable bowel syndrome: an exploration of the patient perspective. Clin Nurs Res 1997;6:156-70.

[18] Kennedy A, Robinson A, Rogers A. Incorporating patients' views and experiences of life with IBS in the development of an evidence based self-help guidebook. Patient Educ Couns 2003;50:303-10. 
[19] O’Sullivan MA, Mahmud N, Kelleher DP, Lovett E, O’Morain CA. Patient knowledge and educational needs in irritable bowel syndrome. Eur J Gastroenterol Hepatolog 2000;12:39-43.

[20] Lahdensuo A, Haahtela T, Herrala J, Kava T, Kiviranta K, Kuusisto P, Peramaki E, Poussa T, Saarelainen S, Svahn T. Randomised comparison of guided self management and traditional treatment of asthma over one year. BMJ 1996;312:74852.

[21] Bengtsson M, Benoni C. IBD-skolan - från idé till praktik (IBD- School - from idea to practice). Mölndal: Hässle Läkemedel AB, 2000.

[22] Robinson A, Thompson DG, Wilkin D, Roberts C. Guided self-management and patient-directed follow-up of ulcerative colitis: a randomised trial. Lancet 2001;358:976-81.

[23] Colwell LJ, Prather CM, Phillips SF, Zinsmeister AR. Effects of an irritable bowel syndrome educational class on health-promoting behaviours and symptoms. Am J Gastroenterol 1998;93:901-5.

[24] Saito YA, Prather CM, Van Dyke CT, Fett S, Zinsmeister AR, Locke GR 3rd. Effects of multidisciplinary education on outcomes in patients with irritable bowel syndrome. Clin Gastroenterol Hepatol 2004;2:576-84.

[25] Thompson WG. Gender differences in irritable bowel symptoms. Eur J Gastroenterol Hepatol 1997;9:299-302.

[26] Simrén M, Abrahamsson H, Svedlund J, Björnsson ES. Quality of Life in patients with irritable bowel syndrome seen in referral centers versus primary care: the impact of gender and predominant bowel pattern. Scand J Gastroenterol 2001;36:545-52. 
[27] Lee OY, Mayer EA, Schmulson M, Chang L, Naliboff B. Gender-related differences in IBS symptoms. Am J Gastroenterol 2001;96:2184-93.

[28] Svedlund, J, Sjödin, I, Dotevall, G. GSRS - a clinical rating scale for gastrointestinal symptoms in patients with irritable bowel syndrome and peptic ulcer disease. Dig Dis Sci 1988;33:129-34.

[29] Dimenäs E, Glise H, Hallerbäck B, Hernqvist H, Svedlund J, Wiklund I. Quality of life in patients with upper gastrointestinal symptoms. An improved evaluation of treatment regimens? Scand J Gastroenterol 1993;28:681-7.

[30] Dimenäs E, Glise H, Hallerbäck B, Hernqvist H, Svedlund J, Wiklund I. Wellbeing and gastrointestinal symptoms among patients referred to endoscopy owing to suspected duodenal ulcer. Scand J Gastroenterol 1995;30:1046-52.

[31] Dupy HJ. The psychological general well-being (PGWB) index. In: Wenger NK, Mattson ME, Furberg CF, Elinson J (Ed.) Assessment of quality of life in clinical trails of cardiovascular therapies. New York: Le Jacq Publishing Inc $1984 ; 170-83$.

[32] Dimenäs E, Carlsson G, Glise H, Israelsson B, Wiklund I. Relevance of norm values as part of the documentation of quality of life instruments for use in upper gastrointestinal disease. Scand J Gastroenterol 1996;31:8-13.

[33] Bengtsson M, Christensson AC. Metodutveckling för systematiserad patientundervisning riktad till personer med crohns sjukdom. (Development of systematic patient education for persons with crohns disease) Malmö: Projektrapport, 1996.

[34] Lustyk MK, Jarett ME, Bennett JC, Heitkemper MM. Does a physically active lifestyle improve symptoms in women with irritable bowel syndrome? Gastroenterol Nurs 2001;24:129-37. 
[35] Shaw G, Srivastava ED, Sadlier M, Swann P, James JY, Rhodes J. Stress management for irritable bowel syndrome: a controlled trial. Digestion 1991;50:3642.

[36] Mayer EA, Gebhart GF. Basic and clinical aspects of visceral hyperalgesia. Gastroenterology 1994;107:271-93.

[37] McKee DP, Quigley EM. Intestinal motility in irritable bowel syndrome: Is IBS a motility disorder? Part 1. Definition of IBS and colonic motility. Dig Dis Sci 1993;38:1761-72.

[38] McKee DP, Quigley EM. Intestinal motility in irritable bowel syndrome: Is IBS a motility disorder? Part 2. Motility of the small bowel, esophagus, stomach, and gall-bladder. Dig Dis Sci 1993;38:1773-82.

[39] Agréus L, Svärdsudd K, Talley N, Jones MP, Tibblin G. Natural history of gastroesophageal reflux disease and functional abdominal disorders: A population based study. Am J Gastroenterol 2002;96:2905-14.

[40] Simrén M, Månsson A, Langkilde AM, Svedlund J, Abrahamsson H, Bengtsson U, Björnsson ES. Food-related gastrointestinal symptoms in the irritable bowel syndrome. Digestion 2001;63:108-15.

[41] Owens DM, Nelson DK, Talley NJ. The irritable bowel syndrome: long-term prognosis and the physician - patient interaction. Ann Intern Med 1995;116:107-12. [42] Bengtsson M, Ohlsson B. Retrospective study of long-term treatment with sodium picosulphate. Eur J Gastroenterol Hepatol 2004;16:433-4.

[43] Farup PG, Hovde O, Torp R, Wtterhus S. patients with functional dyspepsia responding to omeprazole have a chararcteristic gastro-oesophageal reflux pattern. Scand J Gastroenterol 1999;34:575-9. 
[44] Heitkemper M, Carter E, Ameen V, Olden K, Cheng L. Women with irritable bowel syndrome. Differences in patients' and physicans’ perceptions. Gastroenterol Nurs 2002;25:192-200.

[45] Drossman DA. Do psychosocial factors define symptom severity and patient status in irritable bowel syndrome? Am J Med 1999;107:41S-50S.

[46] Gonsakorale WM, Houghton LA, Whorwhell PJ. Hypnotherapy in irritable bowel syndrome: a large-scale audit a clinical service with examination of factros influencing responsiveness. Am J Gastroenterol 2002;97:954-61.

[47] Dobrilla G, Scarpignato C. Placebo and placeboeffect: their impact on the evaluation of drug response in patients. Dig Dis 1994;12:368-77.

[48] Bengtsson M, Ohlsson B. Psychological well-being and symptoms in women with chronic constipation treated with sodium picosulphate. Gastroenterol Nurs 2005;28:3-12

[49] Rankin SH, Stallings KD. Patient education principles \& practice Philadelphia: Lippincott Williams \& Wilkins, 2001 


\section{Legend to figure}

Figure 1. The figure shows the flow chart of the follow-up period after the programme of instruction and the response rate to the questionnaires; the Content of the Information Programme (Con Inf Prog), the Gastrointestinal Symptom Rating Scale (GSRS), the Psychological Rating Scale (PGWB), and the Health Care Consumption (Health Care Cons). 
Table 1. The Gastrointestinal Symptom Rating Scale (GSRS) and the Psychological General Well-Being Index (PGWB) evaluation at baseline and at 12 months after the instruction programme for the 23 responding participants.

\begin{tabular}{|c|c|c|c|c|}
\hline & & $\begin{array}{c}\text { Baseline } \\
(n=23)\end{array}$ & $\begin{array}{l}12 \text { months after instruction } \\
\qquad(n=23)\end{array}$ & $\mathrm{P}$ value \\
\hline \multirow[t]{6}{*}{ GSRS } & Total & $46.0(38.0-53.0)$ & $44.0(34.0-53.0)$ & 0.260 \\
\hline & Reflux & $2.0(2.0-4.0)$ & $2.0(2.0-4.0)$ & 0.068 \\
\hline & Abdominal Pain & $9.0(7.0-11.5)$ & $8.0(5.0-9.0)$ & 0.037 \\
\hline & Constipation & $10.0(6.0-12.0)$ & $11.0(6.0-14.0)$ & 0.164 \\
\hline & Indigestion & $16.0(13.0-20.0)$ & $15.0(10.0-18.0)$ & 0.163 \\
\hline & Diarrhoea & $7.0(5.0-13.0)$ & $6.0(5.0-9.0)$ & 0.163 \\
\hline \multirow[t]{7}{*}{ PGWB } & Total & 86.5 (76.0-101.5) & $88.0(75.0-102.0)$ & 0.616 \\
\hline & Anxiety & $21.0(15.0-25.0)$ & $21.0(18.0-26.0)$ & 0.586 \\
\hline & Depressed mood & $16.0(14.0-17.0)$ & $15.0(14.0-16.0)$ & 0.762 \\
\hline & Pos.Well-being & $15.0(11.5-18.0)$ & $12.0(11.0-16.0)$ & 0.279 \\
\hline & Self-control & $14.0(12.0-16.0)$ & $14.0(10.0-17.0)$ & 0.277 \\
\hline & General health & $12.0(9.0-15.0)$ & $13.0(9.0-14.0)$ & 0.484 \\
\hline & Vitality & $11.0(8.0-14.0)$ & $13.0(10.0-17.0)$ & 0.045 \\
\hline
\end{tabular}

Values are given as medians and inter-quartile ranges. $\mathrm{P}<0.05$ is considered statistical significant; Wilcoxon Signed Rank test. 
Table 2. The number of women out of 20, who consulted a health professional during the 12 months before and the 12 months after the instruction programme and the range of number of visits to each health professional.

During the 12 months

before

the instruction programme
During the 12 months

after

the instruction programme

\begin{tabular}{|c|c|c|c|c|}
\hline & Number* & $\begin{array}{c}\text { The range of } \\
\text { visits per patient }\end{array}$ & Number* & $\begin{array}{c}\text { The range of } \\
\text { visits per patient }\end{array}$ \\
\hline Medical doctor & 15 & $1-9$ & 12 & $1-6$ \\
\hline Registered nurse & 2 & $1-7$ & 3 & $1-4$ \\
\hline Dietician & 5 & $1-4$ & 0 & 0 \\
\hline Med social worker/Psychologist & 1 & 1 & 1 & 10 \\
\hline Physiotherapist/Chiropractor & 1 & 5 & 2 & $6-40$ \\
\hline Masseur/Acupuncturist & 3 & $6-15$ & 3 & $4-10$ \\
\hline Homeopath & 2 & 3- 6 & 2 & $1-2$ \\
\hline
\end{tabular}

*The number of women who reported visits to each type of health professionals

The total number of visits to a physician $(\mathrm{p}<0.037)$ and to a dietician $(\mathrm{p}<0.042)$ was reduced; Wilcoxon Signed Rank test. 
Table 3. The number of women out of 20, who used pharmaceutical drugs and naturopathic preparations before and the 12 months after the instruction programme.

\begin{tabular}{|c|c|c|c|}
\hline & & $\begin{array}{l}\text { During the } 12 \text { months } \\
\text { before } \\
\text { the instruction programme }\end{array}$ & $\begin{array}{l}\text { During the12 months } \\
\text { after } \\
\text { the instruction programme }\end{array}$ \\
\hline & & Number* & Number* \\
\hline \multirow[t]{12}{*}{ Pharmaceutical } & Number of drugs & & \\
\hline & 0 & 8 & 8 \\
\hline & 1 & 6 & 9 \\
\hline & 2 & 3 & 2 \\
\hline & 3 & 3 & 1 \\
\hline & Groups of drugs & & \\
\hline & Bulk forming agents & 7 & 5 \\
\hline & Ulcer healing/Antacids & 6 & 3 \\
\hline & Antifoaming agents & 5 & 5 \\
\hline & Motility stimulants & 2 & 1 \\
\hline & Antidepressant & 1 & 0 \\
\hline & Laxatives & 0 & 2 \\
\hline \multirow[t]{4}{*}{ Naturopathic } & Number of preparations & & \\
\hline & 0 & 14 & 16 \\
\hline & 1 & 4 & 4 \\
\hline & 2 & 2 & 0 \\
\hline
\end{tabular}

*The number of women who reported use of pharmaceutical drugs and naturopathic preparations.

No statistical significant changes were observed; Wilcoxon signed Rank test 
Table 4. The number of women out of 20, sick-leave from work/school and hospitalisation during the 12 months before and the 12 months after the instruction programme.

\begin{tabular}{|c|c|c|c|}
\hline & & $\begin{array}{l}\text { During the } 12 \text { months } \\
\text { before } \\
\text { the instruction programme }\end{array}$ & $\begin{array}{l}\text { During the } 12 \text { months } \\
\text { after } \\
\text { the instruction programme }\end{array}$ \\
\hline & & Number* & Number* \\
\hline \multirow[t]{9}{*}{ Absence from work } & Number of days & & \\
\hline & 0 & 12 & 14 \\
\hline & $1-5$ & 5 & 2 \\
\hline & $6-10$ & 2 & 1 \\
\hline & $11-15$ & 0 & 0 \\
\hline & $16-20$ & 0 & 0 \\
\hline & $21-25$ & 1 & 0 \\
\hline & $26-30$ & 0 & 1 \\
\hline & $>30$ & 0 & 2 \\
\hline \multirow[t]{3}{*}{ Hospitalisation } & Number of days & & \\
\hline & 0 & 19 & 20 \\
\hline & $1-5$ & 1 & 0 \\
\hline
\end{tabular}

*The number of women who reported sick-leave from work/school and hospitalisation.

No statistical significant changes were observed; Wilcoxon Signed Rank test. 
Figure 1.

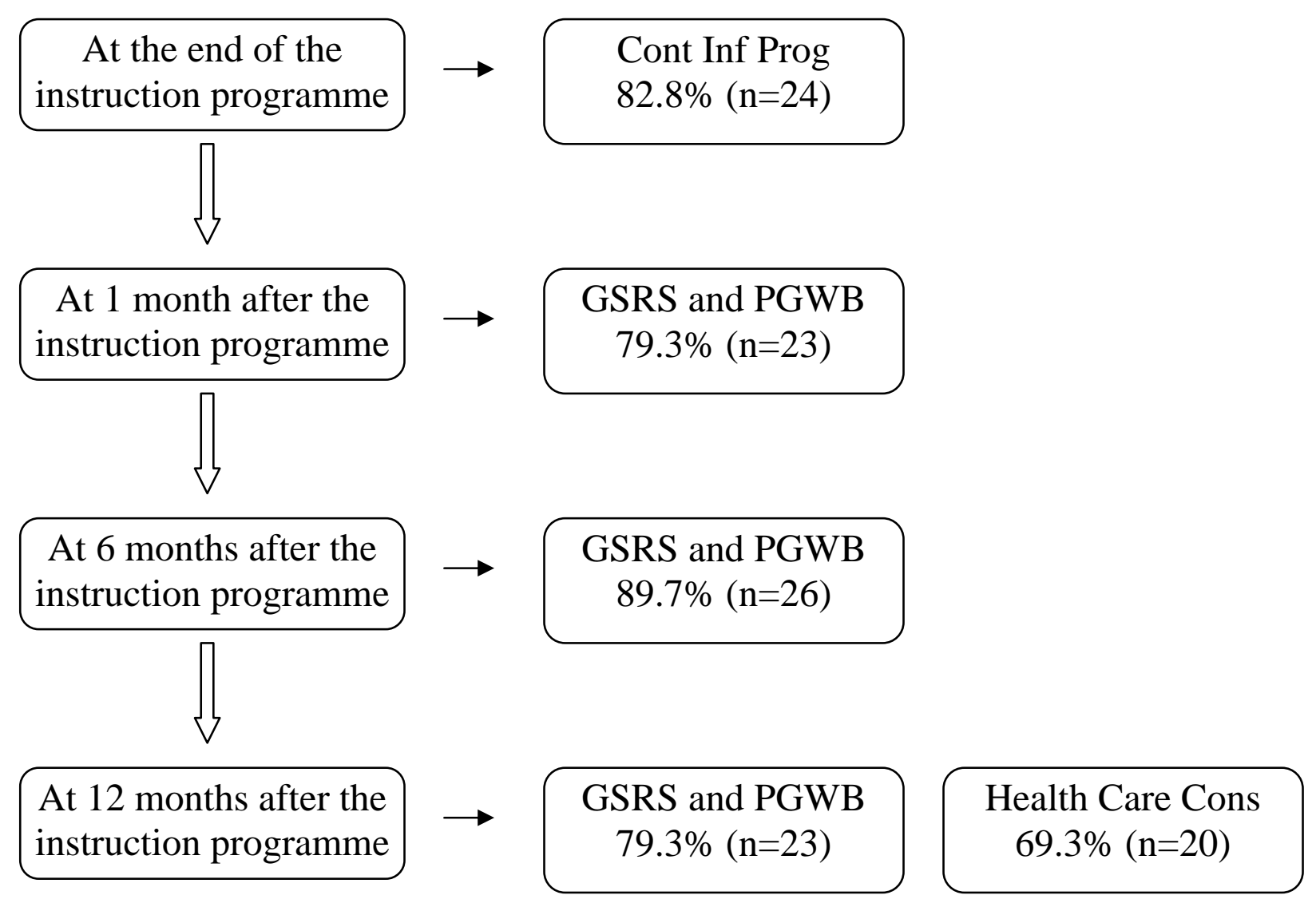

